\title{
Effect of Administration of Metformin on Lipid Profile in Patients with Polycystic Ovary Syndrome after Six Months of Treatment
}

\author{
Rachna Mehandiratta ${ }^{{ }^{*}}$, Purnima Jindal ${ }^{2}$, Vikrom Takkar ${ }^{3}$, Preeti Takkar Kapila ${ }^{4}$, Rajiv Kapila ${ }^{5}$ \\ ${ }^{1 *}$ Associate Professor, Department of Biochemistry, \\ Maharishi Markandeshwar Medical College and Hospital, Kumarhatti, Solan, Himachal Pradesh, India. \\ ${ }^{2}$ Assistant Professor, Department of Biochemistry, Glocal Medical College Superspeciality Hospital \& \\ Research Centre, Mirzapurpole, Saharanpur (U.P.) and Postgraduate from GMC, Patiala, Punjab, India. \\ ${ }^{3}$ Medical Officer, Department of Anaesthesia, District Hospital, Solan, Himachal Pradesh, India. \\ ${ }^{4}$ Resident (IIIrd yr.), Department of Radiology, ${ }^{5}$ Assistant Professor, Department of Orthopedics, \\ Dr. Rajendra Prasad Govt. Medical College, Tanda, Kangra, Himachal Pradesh, India.
}

\section{ABSTRACT}

Objective: Women with polycystic ovary syndrome (PCOS) exhibit risk factors for cardiovascular diseases such as abdominal obesity, insulin resistance and dyslipidemia. Insulin sensitizers, especially metformin, have been shown to improve these metabolic disturbances, but there are only a few studies on their effects on serum lipids in polycystic ovary syndrome. The aim of the present study was to evaluate the effects of metformin on lipid profile changes in patients affected by PCOS.

Methods: In this study, 60 women aged $16-40$ years with PCOS were selected. Diagnostic criteria were based on the diagnostic criteria of PCO syndrome in Rotterdam ESHRE (European Society for Human Reproduction)/ ASRM(American Society of Reproductive Medicine) Sponsored PCOS Consensus Workshop Group (2004). Samples of fasting peripheral blood were taken from all patients to test serum Cholesterol, Low density lipoprotein (LDL), Triglycerides (TG) and High density lipoprotein (HDL) at the start of the treatment and were repeated after 6 months of metformin treatment in a dosage of $1500 \mathrm{mg}$ in divided doses. Also, BMI was compared before and after the treatment.

Results: The mean BMl before treatment was $24.6 \pm 2.9$ $\mathrm{kg} / \mathrm{m}^{2}$ and after treatment was $23.8 \pm 2.8 \mathrm{~kg} / \mathrm{m}^{2}(\mathrm{p}<0.0001)$. The mean cholesterol level before treatment was $192.9 \pm 30.2$ $\mathrm{mg} / \mathrm{dl}$ and after treatment was $174.0 \pm 21.7 \mathrm{mg} / \mathrm{dl}(\mathrm{p}<0.0001)$.

\section{INTRODUCTION}

Polycystic ovary syndrome (PCOS) is a heterogeneous condition characterized by chronic anovulation and hyperandrogenism, and it is typically associated with insulin resistance and hyperinsulinemia - especially in obese women.1,2 This disorder affects women in reproductive age. The signs of PCOS include hyperandrogenism and anovulation. Since the cause of this syndrome has not been diagnosed yet, therefore its treatment will be depending on signs and patient characteristics such as: hirsutism, obesity, menstrual disorder and infertility. ${ }^{3}$
The mean Triglyceride value before treatment was $148.1 \pm 43.2$ $\mathrm{mg} / \mathrm{dl}$ and after treatment was $129.9 \pm 29.6 \mathrm{mg} / \mathrm{dl}(\mathrm{p}<0.0001)$. The mean LDL level before treatment was $127.5 \pm 31.7 \mathrm{mg} / \mathrm{dl}$ and after treatment was $106.8 \pm 21.6 \mathrm{mg} / \mathrm{dl}(\mathrm{p}<0.0001)$. The mean $\mathrm{HDL}$ level before treatment was $36.6 \pm 7.9 \mathrm{mg} / \mathrm{dl}$ and after treatment was $41.1 \pm 6.4 \mathrm{mg} / \mathrm{dl}(\mathrm{p}<0.0001)$.

Conclusion: In women with PCOS, metformin treatment had beneficial effects on lipid profile and therefore it could be useful in the prevention of cardiovascular complications in these women.

Key words: Lipid profile, Metformin, PCO syndrome.

\section{${ }^{*}$ Correspondence to:}

\section{Dr. Rachna Mehandiratta}

Vikrom Niwas,

Jawahar Park Road,

Solan, Himachal Pradesh, India.

Article History:

Received: 28-06-2016, Revised: 17-07-2016, Accepted: 29-07-2016

\begin{tabular}{|l|c|}
\hline \multicolumn{2}{|c|}{ Access this article online } \\
\hline Website: & Quick Response code \\
www.ijmrp.com & \\
\hline DOl: & \\
10.21276/jmrp.2016.2.4.013 & \\
\hline
\end{tabular}

Women with PCOS have an atherogenic lipid profile characterized by lower high-density lipoprotein (HDL) cholesterol and higher triglyceride(TG) and low-density lipoprotein (LDL) cholesterol levels than the age- and weight-matched control women. ${ }^{4-6}$

Metformin, a biguanide antihyperglycemic drug, has been used for decades for the treatment of type 2 diabetes mellitus. In diabetic patients, metformin treatment has been shown to have a beneficial effect on circulating lipid levels by decreasing the concentrations of plasma triglycerides, total and LDL cholesterol 
and by increasing the levels of HDL cholesterol and the HDL: LDL cholesterol ratio, independently of the improvement of glycemic control. ${ }^{7}$ However, there are only a few studies specifically concerning the effects of metformin therapy on the lipid profile in women with PCOS.

Keeping this in mind, the aim of our study was to investigate the effect of metformin on lipid profile changes, in women with PCOS.

\section{MATERIALS AND METHODS}

The present study was conducted in the Department of Biochemistry in collaboration with Department of Obestetrics and Gynaecology, Govt. Medical College, Patiala. The study was approved by the institutional ethical committee.

A total of 60 patients( in the range of $16-40$ years) reporting to the outpatient department of Obestetrics and Gynaecology, Department of Rajindra Hospital, Patiala with clinical features suggestive of PCOS were included in the study.

The presence of any two of the following criteria was used to diagnose PCOS as laid down by the Rotterdam ESHRE/ ASRM Sponsored PCOS Consensus Workshop Group (2004):

- Oligo-ovulation or annovulation

- Clinical and/ or biochemical hyperandrogenism

- Polycystic ovaries and exclusive of congenital adrenal hyperplasia, androgen secreting tumours and Cushing's syndrome.

\section{Selection Criteria}

- Oligomenorrhoea (< 6 cycles/ year), secondary amenorrhoea or hypomenorrhoea (bleeding $<1$ day) with obesity.

- Oligomenorrhoea (<6 cycles/ year), secondary amenorrhoea or hypomenorrhoea (bleeding $<1$ day) with hirsutism.

- Oligomenorrhoea (<6 cycles/ year), secondary amenorrhoea or hypomenorrhoea (bleeding $<1$ day) with acne.

- Oligomenorrhoea (< 6 cycles/ year), secondary amenorrhoea or hypomenorrhoea (bleeding $<1$ day) with infertility.

The menstrual cycle was described as being oligomenorrhoeic (a cycle interval of longer than 35 days but less than six months) amenorrhoeic (no menstruation for more than six months) or hypomenorrhoeic (bleeding lasting less than 1 day).

\section{Exclusion criteria}

1. Infertility due to male factors

2. Infertility due to tubal factors

3. Infertility due to cervical factors

4. Hyperprolactinemia

5. Thyroid disorders

6. Adrenal hyperplasia

7. Cushing's syndrome

8. Androgen producing tumors

The fertility status was classified as "proven fertile" (those with a previous pregnancy and non-subsequent infertility), "fertility untested" (those who had never tried to conceive) or "infertile".

\section{METHODOLOGY}

The patients fulfilling the above criteria were included in the study. A detailed history was recorded with particular reference to menstrual irregularity, obesity, hirsutism, acne and infertility. Informed consent was taken from every patient before including her in the study. It was a 6 month prospective randomized study involving 60 patients of PCOS. Serum levels of Cholesterol, HDL, $\mathrm{LDL}$ and Triglycerides were estimated at the start of treatment and were repeated after 6 months of metformin treatment in a dosage of $1500 \mathrm{mg}$ in divided doses.

Height and weight measurements were done to calculate the BMI. Evidence of hirsutism, acne was looked for.

\section{Assays: Lipid Profile}

Fasting blood sample was collected from the patients and serum was separated for estimation of the following:

1. S.Cholesterol: By in vitro enzymatic colorimetric method. ${ }^{8}$

2. S. Triglycerides: By in vitro enzymatic colorimetric method. ${ }^{9}$

3. Estimation of LDL: By Frieldewald's formula. ${ }^{10}$

LDL-C = Total cholesterol $-(\mathrm{TG} / 5+\mathrm{HDL}-\mathrm{C})$

4. HDL-Cholesterol: By enzymatic method after precipitation of serum by phosphotungstate and magnesium chloride. ${ }^{11}$

SSPS version 13 was used to do the appropriate statistical tests including Student's T Test (two- tailed), Fisher exact test. The results are expressed as means and standard deviation. Differences were considered to be statistically significant if $p$-value was $<0.05$.

Table 1: Distribution of patients according to clinical presentation

\begin{tabular}{lcc}
\hline Clinical Presentation & No. of patients & \%age \\
\hline Menstrual irregularity & 54 & 90 \\
Infertility & 15 & 25 \\
Clinical hyperandrogenism & 43 & 71.67 \\
Overweight & 16 & 26.67 \\
Obesity & 5 & 8.33 \\
Polycystic ovaries on ultrasonography & 50 & 83.33 \\
\hline
\end{tabular}

Note: Discrepancy in total number of patients due to overlapping of symptoms.

Table 2: BMI changes after giving metformin for 6 months

\begin{tabular}{|c|c|c|c|c|c|}
\hline \multicolumn{6}{|c|}{ BMI $\left(\mathrm{kg} / \mathrm{m}^{2}\right)$} \\
\hline & Before & After & $t$ & $P$ & $S$ \\
\hline Range & $20.2-32.5$ & $17.6-31.6$ & 9.72 & $<0.0001$ & HS \\
\hline Mean \pm SD & $24.62 \pm 2.91$ & $23.80 \pm 2.85$ & & & \\
\hline
\end{tabular}


Table 3: Changes in lipid profile after 6 months of treatment with metformin

\begin{tabular}{lcccccc}
\hline \multicolumn{1}{c}{$\begin{array}{c}\text { Parameter } \\
\text { (mg/dl) }\end{array}$} & Before & After & $\mathbf{p}$ & $\mathbf{T}$ & $\mathbf{S}$ & $\%$ Change \\
\hline S.Cholesterol & $192.95 \pm 30.32$ & $174.03 \pm 21.72$ & $<0.0001$ & 6.3 & HS & $\downarrow 9.80$ \\
(mg/dl) & & $129.97 \pm 29.68$ & $<0.0001$ & 6.3 & HS & $\downarrow 12.2 \%$ \\
$\begin{array}{l}\text { Triglyceride levels } \\
\text { (mg/dl) }\end{array}$ & $148 \pm 43.21$ & $106.87 \pm 21.67$ & $<0.0001$ & 5.57 & HS & $\downarrow 16.19 \%$ \\
LDL levels (mg/dl) & $127.52 \pm 31.73$ & $41.1 \pm 6.48$ & $<0.0001$ & 4.34 & HS & $\uparrow 12.08 \%$ \\
HDL levels (mg/dl) & $36.67 \pm 7.94$ & & & & & \\
\hline
\end{tabular}

\section{RESULTS}

In the present study, 60 patients with clinical features suggestive of PCOS who attended the outpatient department of Obstetrics and Gynaecology Department of Rajindra Hospital attached to Govt. Medical College, Patiala were evaluated. Serum levels of serum Cholesterol, HDL, LDL and Triglycerides were estimated and were repeated after 6 months of treatment with metformin.

The study was done over a period of 12 months and the following observations were made. The mean age of patients was $22.8 \pm$ 4.65 years with a range of 16 years to 38 years. The maximum number of patients (25) was in the $21-25$ years age group.

Menstrual irregularity was seen in $90 \%$ of the patients (Oligomenorrhea or secondary amenorrhoea). Infertility was present in $25 \%$ patients while $71.67 \%$ of the patients presented with features of hyperandrogenism. $26.67 \%$ patients were overweight and $8.33 \%$ patients were obese. $83.33 \%$ patients had polycystic ovaries on ultrasonography. Discrepancy in total number of patients was due to overlapping of symptoms. The mean BMl levels before giving treatment were $24.62 \pm 2.91$ $\mathrm{kg} / \mathrm{m}^{2}$ and significantly decreased to $23.80 \pm 2.85 \mathrm{~kg} / \mathrm{m}^{2}$ after giving treatment $(p<0.0001)$. Serum cholesterol levels changed from $192.95 \pm 30.32 \mathrm{mg} / \mathrm{dl}$ before treatment to $174.03 \pm 21.72$ $\mathrm{mg} / \mathrm{dl}(\mathrm{p}<0.0001)$ and there was $9.80 \%$ decrease from the baseline value of cholesterol after giving metformin for 6 months. The mean triglyceride levels before giving treatment was $148.15 \pm$ $43.21 \mathrm{mg} / \mathrm{dl}$ and dropped significantly to $129.97 \pm 29.68 \mathrm{mg} / \mathrm{dl}$ after treatment $(p<0.0001)$. There was a decrease of $12.2 \%$ from the baseline value. The mean LDL levels before giving treatment was $127.52 \pm 31.72 \mathrm{mg} / \mathrm{dl}$ and after giving treatment was $106.87 \pm 21.67 \mathrm{mg} / \mathrm{dl}(p<0.0001)$. There was $16.19 \%$ decrease from the baseline value. The mean HDL levels increased significantly from $36.67 \pm 7.94 \mathrm{mg} / \mathrm{dl}$ before giving treatment to $41.1 \pm 6.48 \mathrm{mg} / \mathrm{dl}$ after giving treatment $(p<0.0001)$ and there was $12.08 \%$ increase from the baseline value.

\section{DISCUSSION}

PCOS is an endocrine disorder seen in women of reproductive age. It describes a convergence of chronic multisystem endocrine derangements including menstrual irregularity, subfertility, obesity, hyperandrogenism, hyperlipidemia and large polycystic ovaries. Also it is a comprehensive syndrome with a variety of associated metabolic disorders which predispose these women to diabetes mellitus, coronary heart disease and myocardial infarction.

PCOS is often perimenarcheal in onset but it has not been extensively investigated in the adolescent population. In the present study, the mean age of the patients was $22.8 \pm 4.6$ years which was comparable to the study conducted by DiamantiKandarakis et al (1999) where the mean age was $24.6 \pm 1.8$ years. ${ }^{12}$ Wijeyratne et al (2002) studied the clinical manifestations of PCOS among South Asians and concluded that South Asians presented at a younger age group as compared to Caucasians. ${ }^{13}$ Balen et al (1995) suggested that there is a substantial heterogeneity of symptoms and signs among women with PCOS. ${ }^{14}$ Several interlinking factors affect the expression of PCOS and for an individual it may change over time. In our study also patients presented with varied clinical presentation including menstrual irregularities (oligomenorrhoea, secondary amenorrhoea), hirsutism, obesity and infertility. High levels of LH and androgens have been regarded as a cause of increased number of oligomenorrhoeic patients under study.

In our study, mean values in BMI decreased significantly. Our results are comparable with the studies conducted by Gleuck et al. ${ }^{15}$ On the contrary; De Leo et al (2002) reported non-significant change in BMI after treatment with metformin. ${ }^{16}$ Reduction in BMI could be explained due to normalization of plasma insulin by metformin resulting in reduced appetite which led to weight reduction in PCOS patients. Our results demonstrated that metformin treatment improved lipid profile i.e. there is significant decrease in serum levels of cholesterol, Triglycerides and LDL-C along with significant increase in HDL-C levels. Our results are in line with previous studies on PCOS, where metformin has been shown to improve the lipid profile, mainly by increasing serum HDL cholesterol concentrations. ${ }^{17,} 18$ Glueck et al (2003) reported a significant decrease in triglyceride levels. ${ }^{15}$ On the other hand, Rautio et al (2005) reported non-significant change in serum cholesterol, Triglycerides and LDL-C levels. ${ }^{19}$ Glueck et al (2003) also showed a significant increase in HDL value from basal levels. ${ }^{15}$ On the other hand, some other studies have shown only a negligible or no effect on lipids in women with PCOS. ${ }^{20,21}$

The discrepancy could be explained by difference in study populations or due to different duration of treatment in various studies. The mechanisms by which metformin improves the lipid profile are not clear. Metformin has been suggested to reduce lipid uptake or synthesis in the intestine and in the hepatocytes. ${ }^{22,}{ }^{23}$ The improvement of obesity and especially abdominal obesity with a subsequent decreased release of free fatty acids (FFAs) from adipose tissue observed during metformin therapy. ${ }^{24-26}$ could also partly explain the improvement of lipid profile during metformin treatment atleast in obese women. Atherosclerosis is more common among women who have anovulation and PCOD. Cheang and et al (2004) showed that metformin not only recommended for PCO patients because of its effect on induction ovulation, but also for its useful influence on lipid metabolism. ${ }^{27}$

In conclusion, the beneficial effects of metformin on the lipid profile strengthen earlier data suggesting that metformin could be an effective drug in the prevention of CVD (Cardiovascular disease) in insulin-resistant women with PCOS. 


\section{REFERENCES}

1. Dunaif $A$, Segal $K R$, Futterweit $W$ \& Dobrjansky A. Profound peripheral insulin resistance, independent of obesity, in polycystic ovary syndrome. Diabetes 1989, 38:1165-1174.

2. Franks S. Polycystic ovary syndrome. New England Journal of Medicine. 1995, 333: 853-861.

3. Ajossa S, Guerriero S, Paoletti AM, Orru M, Melis GB. The treatment of poly cystic ovary syndrome. Minerva Gynecol. 2004, 56: $15-26$.

4. Holte J, Bergh T, Berne C, Wide L \& Lithell H. Restored insulin sensitivity but persistently increased early insulin secretion after weight loss in obese women with polycystic ovary syndrome. Journal of Clinical Endocrinology and Metabolism. 1995, 80: 2586-2593.

5. Talbott E, Guzick D, Clerici A, Berga S, Detre K, Weimer K \& Kuller L. Coronary heart disease risk factors in women with polycystic ovary syndrome. Arteriosclerosis, Thrombosis and Vascular Biology. 1995, 15: $821-826$

6. Talbott E, Clerici A, Berga SL, Kuller L, Guzick D, Detre K, Daniels $T$ \& Engberg RA. Adverse lipid and coronary heart disease risk profiles in young women with polycystic ovary syndrome: results of a case-control study. Journal of Clinical Epidemiology. 1998, 51: 415422.

7. DeFronzo RA \& Goodman AM. Efficacy of metformin in patients with non-insulin-dependent diabetes mellitus. The Multicentre Metformin Study Group. New England Journal of Medicine. 1995, 333: 541- 549 .

8. Allain CC, Porn LS, Chan CS et al: Enzymatic determination of total serum cholesterol. Clin Chem. 1974; 20: 470-475.

9. McGowan MW, Astin JD, Zak B: A peroxidase coupled method for the colorimetric determination of triglycerides. Clin Chem. 1983; 29 : 538-542.

10. Frieldewald WT, Levy RS and Friedricksen DS. Estimation of concentration of low density lipoprotein cholesterol in plasma without rise of preparative ultracentrifuge. Clin Chem. 1972; 18: 499-502.

11. Burstein M, Schalnick HR, Morfin R.Rapid method for the isolation of lipoproteins from human serum by precipitation with polyanions. J Lipid Res.1970; 11: 583.

12. Diamanti-Kandarakis $E$, Kouli CR, Bergiele AT et al. A survey of the polycystic ovary syndrome in the Greek island of Lesbos: hormonal and metabolic porifle. J Clin Endocrinol Metab. 1999; 84(11): 4006-4011.

13. Wijeyaratne $\mathrm{CN}$, Balen $\mathrm{AH}$, Barth JH et al. Clinical manifestations and insulin resistance (IR) in polycystic ovary syndrome (PCOS) among South Asians and Caucasians: is there a difference? Clin Endocrinol. 2002; 57(3): 343-350.

14. Balen AH, Conway GS, Kaltsas $G$ et al. Polycystic ovary syndrome: the spectrum of the disorder in 1741 patients. Hum Reprod 1995; 10(8): 2107-2111.

15. Glueck CJ, Papanna R, Wang P, et al. Incidence and treatment of metabolic syndrome in newly referred women with confirmed polycystic ovary syndrome. Metabolism. 2003; 52(7): 908-15.

16. De Leo V, Antonio La Marca, Raoul Orvieto, and Giuseppe Morgante. Effect of Metformin on Insulin-Like Growth Factor (IGF) I and IGF-Binding Protein I in Polycystic Ovary Syndrome. J Clin Endocrinol Metab. 2000; Vol. 85(4): 1598-1600.

17. Moghetti P, Castello R, Negri C, Tosi F, Perrone F, Caputo M, Zanolin E \& Muggeo M. Metformin effects on clinical features, endocrine and metabolic profiles, and insulin sensitivity in polycystic ovary syndrome: a randomized, double-blind, placebo-controlled 6month trial, followed by open, long-term clinical evaluation. Journal of Clinical Endocrinology and Metabolism. 2000; 85: 139- 146.
18. Fleming R, Hopkinson ZE, Wallace AM, Greer IA \& Sattar N. Ovarian function andmetabolic factors in women with oligomenorrhea treated with metformin in a randomized double blind placebocontrolled trial. Journal of Clinical Endocrinology and Metabolism. 2002; 87: 569-574.

19. Rautio K, Tapananien JS, Rukonen A and Morin-Papunen LC. Effects of metformin and ethinyl estradiol-cyproterone acetate on lipid levels in obese and non-obese women with polycystic ovary syndrome. European Journal of Endocrinology. 2005; 152: 269-275.

20. Ehrmann DA, Cavaghan MK, Imperial J, Sturis J, Rosenfield RL \& Polonsky KS. Effects of metformin on insulin secretion, insulin action, and ovarian steroidogenesis in women with polycystic ovary syndrome. Journal of Clinical Endocrinology and Metabolism. 1997; 82: $524-530$.

21. Velazquez EM, Mendoza S, Hamer T, Sosa F \& Glueck CJ. Metformin therapy in polycystic ovary syndrome reduces hyperinsulinemia, insulin resistance, hyperandrogenemia, and systolicblood pressure, while facilitating normal menses and pregnancy.Metabolism: Clinical and Experimental. 1994;43: 647-654. 22. Carlsen SM, Rossvoll O, Bjerve KS \& Folling I. Metformin improves blood lipid pattern in nondiabetic patients with coronary heart disease. Journal of Internal Medicine. 1996; 239: 227-233.

23. Marquie $G$. Metformin action on lipid metabolism in lesions of experimental aortic atherosclerosis of rabbits. Atherosclerosis .1983; 47: 7-17.

24. Morin-Papunen L, Vauhkonen I, Koivunen R, Ruokonen A, Martikainen H \& Tapanainen JS. Metformin versus ethinyl estradiolcyproterone acetate in the treatment of nonobese women with polycystic ovary syndrome: a randomized study. Journal of Clinical Endocrinology and Metabolism. 2003; 88: 148-156.

25. Morin-Papunen LC, Vauhkonen I, Koivunen RM, Ruokonen A, Martikainen HK \& Tapanainen JS. Endocrine and metabolic effects of metformin versus ethinyl estradiol-cyproterone acetate in obese women with polycystic ovary syndrome: a randomized study. Journal of Clinical Endocrinology and Metabolism. 2000; 85: 3161-3168.

26. Pasquali R, Gambineri A, Biscotti D, Vicennati V, Gagliardi L, Colitta D, Fiorini S, Cognigni GE, Filicori M \& Morselli-Labate AM. Effect of long-term treatment with metformin added to hypocaloric diet on body composition, fat distribution, and androgen and insulin levels in abdominally obese women with and without the polycystic ovary syndrome. Journal of Clinical Endocrinology and Metabolism. 2000; 85: 2767-2774.

27. Cheang KI, Nestler JE. Should insulin -sensitizing drugs be used in the treatment of poly cystic ovary syndrome? Reprod Biomed Online. 2004, 8: 440-7.

\section{Source of Support: Nil. Conflict of Interest: None Declared.}

Copyright: (c) the author(s) and publisher. IJMRP is an official publication of Ibn Sina Academy of Medieval Medicine \& Sciences, registered in 2001 under Indian Trusts Act, 1882. This is an open access article distributed under the terms of the Creative Commons Attribution Non-commercial License, which permits unrestricted noncommercial use, distribution, and reproduction in any medium, provided the original work is properly cited.

Cite this article as: Rachna Mehandiratta, Purnima Jindal, Vikrom Takkar, Preeti Takkar Kapila, Rajiv Kapila. Effect of Administration of Metformin on Lipid Profile in Patients with Polycystic Ovary Syndrome after Six Months of Treatment. Int J Med Res Prof. 2016; 2(4):66-69. 